\title{
DESAFIOS E PERSPECTIVAS DAS AÇÕES EDUCATIVO- AMBIENTAIS NA EDUCAÇÃO INFANTIL
}

Daniela Gureski Rodrigues ${ }^{1}$

Vanessa Marion Andreoli²

Resumo: Sabe-se que a Educação Ambiental deveria fazer-se presente em todos os níveis de ensino, inclusive na Educação Infantil. Desta maneira, o presente artigo, buscou responder a seguinte questão: Como desenvolver práticas educativo-ambientais em um Centro Municipal de Educação Infantil em Curitiba/Paraná, a partir de ações interdisciplinares? Para tanto, procurou-se identificar a percepção que os profissionais possuem sobre o trabalho com a EA e a interdisciplinaridade; buscando sensibilizar os profissionais e promover práticas de EA, através da interdisciplinaridade. Para a realização fez-se o uso da abordagem qualitativa, utilizando como instrumento a entrevista e a pesquisa-ação. Sendo assim, destaca-se a necessidade de uma formação mais abrangente dessas profissionais para que sejam repertoriadas para trabalhar com tal temática.

Palavras-chave: Educação Ambiental; Educação Infantil; Interdisciplinaridade.

2 Universidade Federal do Paraná. E-mail: vanessaandreoli@ufpr.br 


\section{A Educação Ambiental na Educação Infantil}

Para que se compreenda melhor o foco deste trabalho, faz-se necessário um caminhar pela trajetória da Educação Ambiental, para que dessa maneira possa se perceber a importância de trabalhar este segmento em todos os níveis da educação.

As questões ambientais já vêm sendo discutidas há muitas décadas e a medida que surgem novas intervenções e propostas, o conceito de Educação Ambiental vai se modificando e, principalmente, a maneira de se trabalhar com esta temática.

No ano de 1972 ocorreu na Suécia o primeiro evento mundial para discutir questões sobre a preservação do meio ambiente, a Conferência de Estocolmo. Nela, foi escrito o Plano de Ação Mundial que reconheceu a Educação Ambiental como um elemento para combater a crise ambiental, que passa a apreciar a Educação Ambiental no campo de ação pedagógica, segundo Morales (2009).

Para aprofundar as discussões e complementar a Conferência de Estocolmo, foi realizada no ano de 1975 a Conferência de Belgrado, da qual se originou a Carta de Belgrado, documento que, segundo Medina (1994)

[...] preconizou a necessidade de uma nova ética global, capaz de promover à erradicação a pobreza, da fome, do analfabetismo, da poluição, da exploração e dominação humana, e censura do desenvolvimento de uma nação às custas de outra, acentuando a premência de formas de desenvolvimento que beneficiem toda a humanidade (p.29).

Esse evento foi um grande marco na área da Educação Ambiental, pois lançou-se o Programa de Educação Ambiental (PIEA), o qual formula os seguintes princípios orientadores: a Educação Ambiental deve ser continuada, multidisciplinar, integrada às diferenças regionais e voltada para os interesses nacionais. No ano de 1977, na Geórgia, ocorreu a Conferência de Tibilisi que teve como documento oficial a Declaração da Educação Ambiental, a qual foi decisiva para os rumos da EA em todo o mundo. Para Morales (2009),

Nessa Conferência postulou-se que a educação ambiental é elemento essencial para a educação global, orientada para a resolução dos problemas por meio da participação ativa dos educandos na educação formal e não-formal, em favor do bemestar da comunidade humana. Acrescentou também, aos princípios básicos da educação ambiental, a importância que é dada às relações entre natureza e sociedade, 0 que posteriormente, na década de 1980, deu origem à vertente socioambiental da educação ambiental (p.42). 
No ano de 1992, no Rio de Janeiro, realizou-se a Conferência das Nações Unidas para o Meio Ambiente e Desenvolvimento (CNUMAD) RIO 92, a qual culminou em documentos de suma importância para a educação brasileira, dentre os quais, a Agenda 21, que sistematizou um plano de ações com o objetivo de alcançar o desenvolvimento sustentável; a Carta da Terra que é uma declaração de princípios éticos e fundamentais para se construir uma sociedade global justa, sustentável e pacífica e o Tratado de Educação Ambiental para Sociedades Sustentáveis, no qual são destacadas ações como o incentivo à produção de conhecimento, a instituições que tenham compromisso com a sustentabilidade e movimentos sociais na melhoria da qualidade de vida e do meio ambiente.

Neste período, houve ainda, o Programa Nacional de Educação Ambiental (1994), tendo como um de seus objetivos a promoção de processos de EA em todos os níveis de ensino, além de fomentar processos de formação continuada na EA. No ano de 1997, houve o lançamento dos Parâmetros Curriculares Nacionais, os quais foram produzidos com base na LDB e que definiu a EA como tema transversal. Ainda nos anos 90, em 1999, houve a instituição da Política Nacional de Educação Ambiental, a qual é de suma importância para a garantia do direito à EA.

$O$ século $X X$ ainda trouxe diversas discussões no âmbito da $E A$ e, no ano de 2012, ocorreu a RIO + 20 realizada no Rio de Janeiro, tendo como foco a "economia verde no contexto do desenvolvimento sustentável e da erradicação da pobreza e a estrutura institucional para o desenvolvimento sustentável". O principal objetivo desta conferência foi a renovação do compromisso político com o desenvolvimento sustentável.

No que diz respeito às Leis que discutem a Educação Ambiental no Brasil, temos a Lei n. 9.795, de 27 de abril de 1999, que estabelece em seu artigo 9 que a Educação Ambiental deve ser desenvolvida no âmbito escolar dos currículos, englobando todos os níveis de ensino.

Destaca-se ainda, a Resolução no 2, de 15 de junho de 2012, que estabelece as Diretrizes Curriculares Nacionais para a Educação Ambiental (DCNEA), que em seu artigo 8을 estabelece que:

A Educação Ambiental, respeitando a autonomia da dinâmica escolar e acadêmica, deve ser desenvolvida como uma prática educativa integrada e interdisciplinar, contínua e permanente em todas as fases, etapas, níveis e modalidades, não devendo, como regra, ser implantada como disciplina ou componente curricular específico (BRASIL, 2012).

Dessa maneira a Educação Infantil está englobada nesse contexto e deve, assim como os demais níveis de educação, oferecer práticas que contemplem a EA. Dentre os documentos relacionados à educação podemos citar primeiramente os Referenciais Curriculares Nacionais para a Educação Infantil (RCNEI), o qual traz em seus objetivos gerais que a criança precisa: Revbea, São Paulo, V. 11, № 4: 130-148, 2016. 
"observar e explorar o ambiente com atitude de curiosidade, percebendo-se cada vez mais como integrante, dependente e agente transformador do meio ambiente e valorizando atitudes que contribuam para a sua conservação". (BRASIL, 1998, vol.1, p.63).

Ainda, nestes documentos, pode-se ressaltar as Diretrizes Curriculares Nacionais para Educação Infantil de 2009, que apontam alguns princípios a serem respeitados a se trabalhar na Educação Infantil:

As propostas pedagógicas de Educação Infantil devem respeitar os seguintes princípios: I - Éticos: da autonomia, da responsabilidade, da solidariedade e do respeito ao bem comum, ao meio ambiente e às diferentes culturas, identidades e singularidades; II - Políticos: dos direitos de cidadania, do exercício da criticidade e do respeito à ordem democrática; III Estéticos: da sensibilidade, da criatividade, da ludicidade e da liberdade de expressão nas diferentes manifestações artísticas e culturais (BRASIL, 2009).

Dessa maneira, pode-se dizer que, esses documento,s reconhecem a importância de trabalhar a Educação Ambiental, no entanto, destaca-se que os profissionais que atuam, principalmente na Educação Infantil, devem levar em consideração uma formação crítica e transformadora buscando superar a Educação Ambiental conservadora e, além disso, integrar a Educação Ambiental em todas as disciplinas.

É necessário estabelecer um saber crítico e reflexivo, no qual o aluno não tem uma disciplina específica e recebe os conteúdos prontos e acabados, mas é levado a refletir e fazer interações sobre o que está aprendendo. Sabese que, desde o ano de 1997, os Parâmetros Curriculares Nacionais (BRASIL, 1997) trouxeram a temática Meio Ambiente como um tema transversal, ou seja, um tema a ser trabalhado vinculando a todas as áreas de conhecimento e que, desde então, muitas discussões acerca deste assunto, ocorreram a níveis mundiais, para que se encontrasse uma melhor maneira de abordar as questões ambientais em sala de aula.

Para Caride e Meira (2004),

[..] a educação ambiental é uma educação social, política e moral, que além de pretender sensibilizar ou melhorar a formação ambiental das pessoas, também aspira a revelar e problematizar as suposições ideológicas em que fundamenta a ação humana (2004, p.244).

A interdisciplinaridade é mencionada em importantes documentos como a Declaração de Estocolmo (1972), Carta de Belgrado (1975), Declaração de Tbilisi (1977) e as DCNEA (2012), sendo considerada como um caminho para 
trabalhar a Educação Ambiental. As DCNEA asseguram em seu artigo $8^{\circ}$ que a Educação Ambiental seja realizada em todos os níveis escolares como uma prática educativa integrada e interdisciplinar. Afirma-se que, a Educação Ambiental não deve ser implementada como disciplina ou componente curricular específico, desta maneira, a interdisciplinaridade seria uma alternativa para trabalhar com essa temática. Para Yared (2013) "Etimologicamente, interdisciplinaridade significa, em sentido geral, relação entre as disciplinas." (p.167). Ou seja, A Educação Ambiental não deve ser uma disciplina isolada, mas deve ser trabalhada paralelamente com outras disciplinas, fazendo uma ponte, uma ligação. Então, pode-se dizer que, uma disciplina em si, não daria conta de tais problematizações, da construção de valores, da politização, do trabalho reflexivo, pois este é um trabalho que vai sendo construído aos poucos, com compromisso docente e mudança de postura. Para Reigota (2009),

Com a educação ambiental, a tradicional separação entre as disciplinas, humanas, exatas e naturais, perde o sentido, já que o que se busca é o diálogo de todas elas para encontrar alternativas e solução dos problemas ambientais (p.46).

Sendo assim, a interdisciplinaridade seria uma maneira de trabalhar a Educação Ambiental, levando em consideração que denota algumas especificidades como a quebra da fragmentação das disciplinas, buscando relacionar disciplinas para o enfrentamento de temas de estudo, também visa construir conhecimento rompendo os limites das disciplinas buscando articular interesses em comum. Segundo Tozzoni-Reis (2009), "o trabalho interdisciplinar pode então ser tomado como possibilidade de quebrar a rigidez dos compartimentos em que se encontram isoladas as disciplinas" (p.86).

Desta maneira, é possível estabelecer um saber crítico e reflexivo, no qual, o aluno não tem uma disciplina específica e recebe os conteúdos prontos e acabados, mas é levado a refletir e fazer interações sobre o que está aprendendo. Sabe-se que, desde o ano de 1997, os Parâmetros Curriculares Nacionais (BRASIL, 1997) trouxeram a temática Meio Ambiente como um tema transversal, ou seja, um tema a ser trabalhado vinculando todas as áreas de conhecimento e que, desde então, muitas discussões a cerca desse assunto ocorreram a níveis mundiais, para que se encontrasse uma melhor maneira de abordar as questões ambientais em sala de aula. Para Leff (2012):

A construção dessa racionalidade exige a transformação dos paradigmas científicos tradicionais e a produção de novos conhecimentos, o diálogo, hibridação e integração de saberes, assim como a colaboração de diferentes especialidades, propondo a organização interdisciplinar do conhecimento para o desenvolvimento sustentável (p.207). 
Contudo, fica clara a necessidade de uma formação para esses docentes que possibilite trabalhar as questões ambientais de maneira interdisciplinar, buscando a interação entre tais disciplinas, para que os alunos envolvidos neste processo não adquiram uma visão fragmentada da Educação Ambiental, achando que o que acontece em determinados lugares, nada reflete na vida deles, mas que adquiram ao longo de sua formação, uma visão global.

Buscando assim, que os indivíduos trabalhem a partir da realidade, que sejam reflexivos, que ajam diante das questões socioambientais, que busquem envolver a comunidade, que trabalhem coletivamente, espera-se uma mudança de postura frente à realidade que estão inseridos. É preciso que os docentes também mudem sua postura e estimulem os alunos a realizarem atividades que revelem sentimentos de companheirismo, solidariedade, respeito. Segundo Tiriba (2010):

[...] pois não apenas as salas de aula, mas todos os lugares são propícios às aprendizagens: terreiros, jardins, plantações, criações, riachos, praias, dunas, descampados; tudo que está entorno do bairro, a cidade, seus acidentes geográficos, pontos históricos e pitorescos, as montanhas, o mar... Além de se constituírem com espaços de brincar livremente e relaxar, estes locais podem também ser explorados como lugar de ouvir histórias, desenhar e pintar, espaços de aprendizagem, em que se trabalha uma diversidade de conhecimento (p.9).

Desta maneira, é essencial que os professores explorem os espaços, lembrando que a Educação Ambiental envolve todas as escalas, ou seja, a própria casa, a rua, o bairro, a escola, o município, o estado, o país e o mundo e seria impossível pensar em questões ambientais apenas em nível global ou nacional, principalmente na Educação Infantil, na qual a criança precisa vivenciar, experimentar, sentir, necessitando de situações concretas para efetivar sua aprendizagem. Sendo assim, é essencial que as problematizações resultem das vivências das crianças. Sobre isso, Carvalho (2012) afirma ainda que a Educação Ambiental deve oferecer:

Uma aprendizagem em seu sentido radical, a qual, muito mais do que apenas prover conteúdos e informações, gera processos de formação do sujeito humano, instituindo novos modos de ser, de compreender, de posicionar-se ante os outros e a si mesmo, enfrentando os desafios e as crises do tempo em que vivemos (2012, p.69).

Ou seja, que busquemos formar cada vez mais indivíduos reflexivos, críticos, questionadores, que busquem ações para as resoluções de problemas e não indivíduos passivos, que apenas ouvem o conteúdo que lhe é transmitido, não fazendo reflexão alguma sobre a sociedade que o cerca. 


\section{Caracterização do campo de pesquisa e dos particantes}

A presente pesquisa-ação foi realizada no Centro Municipal de Educação Infantil (CMEI) Cora Coralina na cidade de Curitiba, Paraná, onde a base do trabalho é o cuidar e o educar alicerçado pelas brincadeiras, buscando desenvolver a autonomia das crianças. O CMEI tem atualmente três turmas sendo elas: um maternal II e III e um pré, com um total de 60 crianças, as quais são atendidas em período integral.

Conta com 14 funcionários, sendo 8 professoras de Educação Infantil, 1 auxiliar administrativo, 1 pedagoga, 1 diretora e, ainda, o suporte técnico que conta com 2 auxiliares de serviços gerais e 1 auxiliar de cozinha.

O CMEI já existe há mais de 20 anos, no entanto, era um Centro Municipal de Educação Infantil chamado Jardim Savana e só passou a integrar à Rede Municipal e se intitular Centro Municipal de Educação Infantil Cora Coralina, no ano de 2013. O CMEI está localizado no bairro Uberaba, mais conhecido como Uberaba de Baixo. Ao entorno do CMEI existe uma periferia, com um alto índice de criminalidade e carência por parte da população.

\section{Etapas}

\section{Entrevista}

A necessidade deste projeto de intervenção surgiu da observação diária das práticas de Educação Ambiental que ocorriam no CMEI, as quais, sempre me chamaram a atenção e despertaram a curiosidade em saber o que as professoras que realizavam essas práticas, compreendiam sobre o trabalho com a EA. Desta maneira, como primeiro passo para este projeto, decidi investigar as professoras para que, assim, pudesse-se fazer algumas ações que atingissem não apenas as crianças, mas a instituição como um todo. Sendo assim, iniciei com uma entrevista com as professoras.

Segundo Bogdan (1994) a entrevista é um dos principais instrumentos utilizados em pesquisas, pois através dela, o investigador pode atingir diferentes públicos e tratar sobre variados assuntos, e o mais importante, tratando a entrevista como um diálogo, o investigador pode se aprofundar no assunto dando liberdade ao entrevistado.

Para a realização das entrevistas foram elaboradas duas perguntas, as quais abordaram questões relacionadas ao trabalho realizado com a EA na Educação Infantil e a percepção dos entrevistados sobre essa temática.

Desta maneira, para dar início à pesquisa, foram entrevistas cinco professoras de Educação Infantil, as quais, em sua totalidade, possuem formação inicial em pedagogia, sendo que, duas possuem, pós em Educação Especial e uma em Educação Infantil. A idade das entrevistadas variou de 26 a 52 anos. Quanto ao tempo de atuação na docência houve uma variável de dois a 11 anos.

$$
\text { Como é possível notar, os sujeitos participantes da pesquisa }
$$


compuseram um diversificado grupo ao que diz respeito à idade e ao tempo de atuação, no entanto, ao se tratar da formação, houve uma unanimidade de formação em pedagogia.

O primeiro aspecto analisado na pesquisa foi à concepção que essas professoras possuíam da Educação Ambiental. Para Tozoni-Reis

Compreendemos a educação ambiental crítica, baseada no materialismo histórico dialético, considerando os ideais democráticos e emancipatórios para a prática de uma educação facilitadora na construção social de conhecimentos implicados na vida do sujeito, nas relações dos sujeitos com o ambiente - natural e social - em que ele vive (2014, p.11).

Pode-se dizer que, a partir das entrevistas, a percepção que as professoras possuem sobre a educação nada tem a ver com uma Educação Ambiental crítica e transformadora, mas sim, com uma Educação Ambiental naturalista e conservadora, como consta no depoimento de algumas delas:

"É a conscientização do meio ambiente, é mostrar para as pessoas que temos que preservar a natureza" (P2).

"É trabalhar com as crianças a importância de cuidar das plantas e dos animais" (P3).

"É a educação voltada para à conservação do meio ambiente" (P5).

Ou seja, encontra-se aqui, a necessidade de repertoriar essas professoras, de oferecer uma formação para que as mesmas compreendam a importância do trabalho com a EA, mostrando que existem outras maneiras para que esse trabalho seja realizado.

O outro aspecto analisado nas entrevistas diz respeito a como é desenvolvido o trabalho com Educação Ambiental nessa instituição de Educação Infantil. Compreende-se que, as professoras realizam um trabalho com a EA da maneira que compreendem a temática, sendo assim, pode-se afirmar que, o trabalho realizado na maioria das vezes, não envolve as crianças. Tais constatações, são apenas passivos diante das informações que recebem. Destaca-se a fala de duas professoras: 
"Ensinar para as crianças como separar o lixo, conscientizar sobre a poluição e o desmatamento. E como você trabalha essas temáticas? Aqui no CMEI tem um projeto de reciclagem: os pais trazem o lixo, as professoras separam e vendem para arrecadar dinheiro para o CMEI. E as crianças participam? Sim, elas ajudam os pais trazendo os recicláveis para o CMEl" (P2).

"Seria trabalhar de forma prática a conscientização e o contato com a natureza. E como você realiza esse trabalho? Faço momentos ao ar livre, onde elas brincam no espaço externo e falo para elas cuidarem das plantas que estão no CMEl" (P3).

Outra questão levantada diante da realização das entrevistas é o projeto desenvolvido no CMEI sobre reciclagem, o qual as crianças deveriam ser as protagonistas, no entanto, o que se percebe é que, quem desempenha esse papel são os pais e as professoras, e as crianças em sua grande maioria, nem sabem o que todo esse lixo está fazendo na instituição. Segundo Tozoni-Reis (2014)

A educação ambiental desenvolvida no ambiente escolar é de forma bastante diferente da educação ambiental que problematiza que é crítica e questionadora. Isso mostra o quanto temos que lutar, não somente por melhores condições de trabalho e de educação, mas também por uma formação de professores que possibilite um suporte teórico-metodológico (2014, p.23).

Desta maneira, após as entrevistas e o levantamento de dados, compreendi a necessidade de primeiramente conversar com as professoras sobre o trabalho realizado no CMEI e buscar inserir na prática desses sujeitos outra maneira de trabalhar a EA, repertoriando e discutindo ações que podem ser realizadas na El de maneira crítica e reflexiva.

\section{Pesquisa-Ação}

Neste segundo momento, a metodologia utilizada passou a ser a pesquisa-ação, a qual articula o conhecimento com a busca de solução de problemas, além do mais, a ação deve necessariamente ocorrer, após um período de reflexão e tomada de decisão por todo o grupo (Thiollent, 2000).

Ainda para Elliott (1997) a pesquisa-ação

[...] permite superar as lacunas existentes entre a pesquisa educativa e a prática docente, ou seja, entre a teoria e a prática, e os resultados ampliam as capacidades de compreensão dos professores e suas práticas, por isso favorecem amplamente as mudanças (p.15). 
Desta maneira, o partícipe da pesquisa, encontra-se em contato direto com a teoria, buscando promover uma reflexão que repercuta diretamente em sua prática, ressaltando que, a pesquisa-ação, é democrática e contribui para uma mudança social.

Com o propósito de levar o grupo a refletir sobre suas ações, foi marcado um encontro em sábado pedagógico, no qual fizemos um levantamento das ações realizadas no $\mathrm{CMEI}$, e levei um texto para reflexão: "Crianças da natureza: Educação Ambiental para Sociedades Sustentáveis" da autora Léa Tiriba e algumas práticas realizadas em outras instituições públicas e particulares. Após a leitura do texto e a polêmica das atividades realizadas nas outras instituições, comecei a questioná-las sobre o que achavam do trabalho realizado no nosso CMEl e o que poderíamos melhorar, sendo assim, elencamos uma lista de atitudes citadas pelas professoras (Tabela 1):

Tabela 1: Atitudes de melhoria.

\begin{tabular}{|l|l|}
\hline \multicolumn{1}{|c|}{ Atitudes } & \multicolumn{1}{c|}{ Motivo } \\
\hline $\begin{array}{l}\text { Envolver as crianças no projeto de } \\
\text { reciclagem. }\end{array}$ & $\begin{array}{l}\text { O projeto é para elas e elas são as que } \\
\text { menos participam. }\end{array}$ \\
\hline Melhorar o trabalho com a horta da escola. & $\begin{array}{l}\text { As crianças nem vão até a horta, são os pais } \\
\text { que plantam, sendo que a horta é das } \\
\text { crianças. }\end{array}$ \\
\hline Inserir a turma do MII nos projetos. & $\begin{array}{l}\text { Eles sempre ficam de fora por serem os } \\
\text { menores, mas eles também podem aprender } \\
\text { muito. }\end{array}$ \\
\hline
\end{tabular}

As professoras elencaram essas três ações para dar início, destacando o porquê gostariam de realizá-las. A partir de então, demos início ao trabalho com as crianças. Em meio a diversas reflexões e discussões, a primeira atitude tomada pelo grupo foi acabar com o projeto de reciclagem, por acreditarem que não fazia sentido manter esse no $\mathrm{CMEl}$, sendo que elas não estavam envolvidas o suficiente para que pudessem envolver as crianças. Algumas destacaram que achavam muito trabalhoso dedicar-se de maneira crítica e reflexiva a este projeto e que as crianças eram pequenas demais para compreender a complexidade do mesmo

A segunda ação realizada no CMEI, foi melhorar o trabalho realizado com a horta, o que foi realmente gratificante, pois toda a equipe se envolveu nesta questão. Demos início instrumentalizando às crianças, a partir das rodas de conversa, depois com figuras de hortas e verduras. Levamos vídeos infantis sobre a importância de uma alimentação saudável e, junto com elas, foi decido o que se plantaria na horta. Cada sala teve seu espaço reservado na horta, onde as crianças escolheram as mudas trazidas pelo horto da Prefeitura e, junto com um pai do conselho CEMEl, as plantavam e nomeavam com a ajuda das professoras o que havia em cada horta. Ao longo deste processo, as crianças acompanharam o crescimento das mudas e fizeram registros e rodas de conversa sobre o que iriam fazer quando nascesse o que haviam plantado. 
Decidiram então, optar pela alimentação saudável e, quando nasceram os pés de alface, beterraba e cenoura, as crianças, juntamente com as professoras, fizeram um sanduíche natural.

A partir de então, as crianças realmente se envolveram com a horta. Elas mesmas traziam pesquisas de casa sobre a alimentação saudável, sobre o que poderiam plantar na horta e o que poderiam fazer quando nascesse aquele alimento. As professoras também se envolveram muito neste processo e houve uma troca efetiva entre alunos e professoras na construção deste conhecimento. Para Oliveira (2014)

(...) a construção de uma horta no ambiente escolar apresentase como uma excelente ferramenta geradora de conhecimento, tornando-se um elemento capaz de desenvolver a interdisciplinaridade envolvendo ciências e a arte, abordando conceitos teóricos e práticos para atingir diferentes temas transversais (2014, p.197).

Ou seja, um trabalho no qual, os alunos são os protagonistas e compreendem o porquê de determinadas ações, o que garante a aprendizagem, a reflexão, a autonomia dos envolvidos e com certeza uma troca de saberes.

Como terceira ação realizada no $\mathrm{CMEI}$, mais focada neste projeto, foi desenvolvida com a minha própria turma, a qual contava com 20 crianças, com idades entre três e cinco anos. A Prefeitura Municipal de Curitiba lançou um projeto chamado "Espaço Externo" que consistia em fazer alguma ação que mudasse o espaço externo dos CMEIS, que os tornassem mais agradáveis e atrativos para as crianças. Dessa maneira decidi focar nesse projeto da rede.

Para dar início ao projeto, eu e a professora que atuava comigo em sala, fizemos uma roda de conversa. Contamos para as crianças sobre o projeto e, então, levamos as crianças para o espaço externo do CMEI, o qual era bem amplo, possuía muita grama, no entanto, o único lugar aproveitado por elas, era o parque de areia, pois a parte com grama acabava não sendo muito atrativa (Figura 1). Chegando no espaço, ouvimos das crianças o que elas queriam como melhoria para aquele local. 


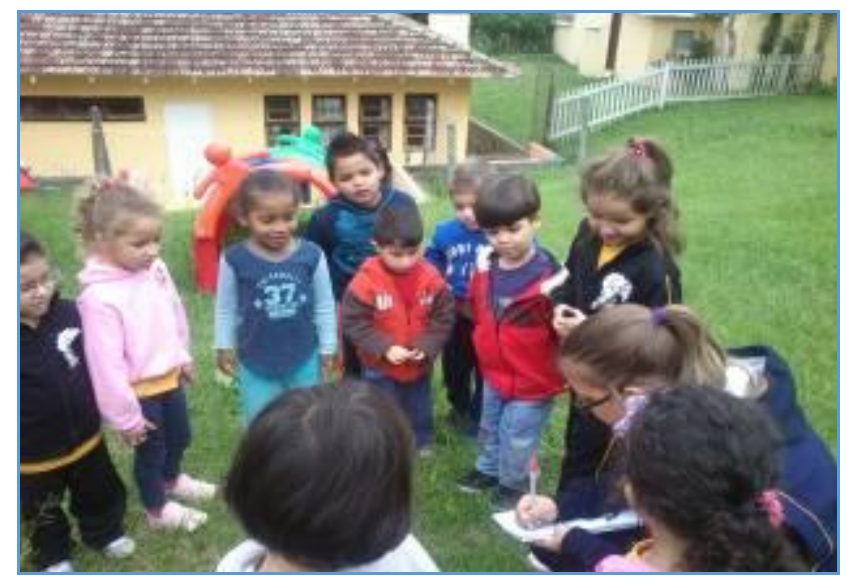

Figura1: As crianças no espaço externo e a professora anotando as ações citadas pelas crianças.

Após essa ida ao espaço externo, voltamos para a sala e então fizemos uma lista de tudo o que as crianças haviam falado (Figura 2).

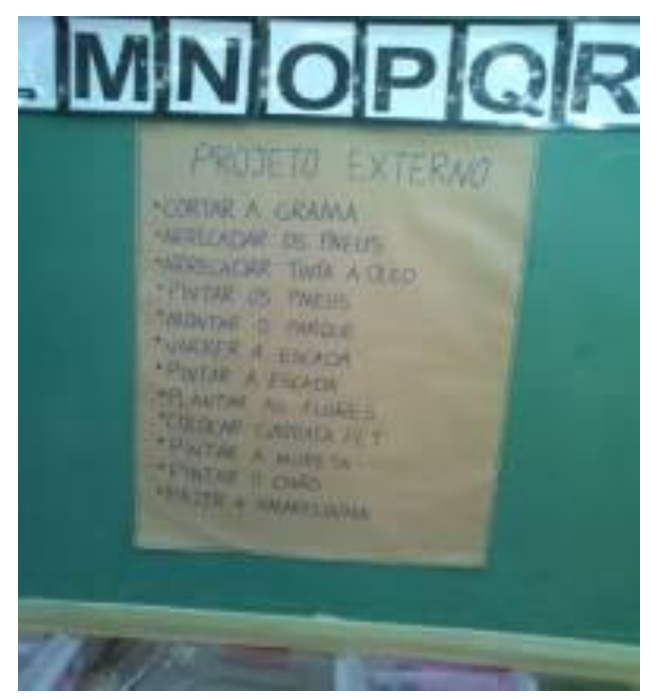

Figura 2: Lista realizada com as crianças.

Após construir a lista e pendurá-la na sala, iniciamos uma problematização com as crianças como, por exemplo, quem iria cortar a grama? Como conseguiríamos a tinta para pintar os pneus e as escadas? Como faríamos para pintar tudo isso? E para fazer o parque quem nos ajudaria?

Portanto, as crianças foram levadas à reflexão e logo responderam, buscando solução para os problemas propostos, por meio de uma proposição de ações.

Primeiramente, convidamos a direção do CMEI para ir até a nossa sala e falarmos sobre o nosso projeto, depois, a diretora falou para as crianças que a 
primeira ação imediata que poderia ser tomada era o corte da grama, sendo assim, ela logo entrou em contato com a Prefeitura e, na mesma semana, a grama foi cortada.

Depois, a turma do pré fez alguns cartazes para pedir a colaboração dos pais para arrecadar tinta, tanto para pintar os pneus, como a escada e a amarelinha. Enquanto esses materiais não chegavam, sugerimos a construção de uma floreira, já que as crianças queriam plantar flores no CMEl.

Durante a roda de conversa, as crianças escolheram através de imagens o tipo de floreira que elas queriam fazer, depois, arrecadamos as garrafas pet e pedimos terra e mudas do horto da prefeitura (Figura 3).

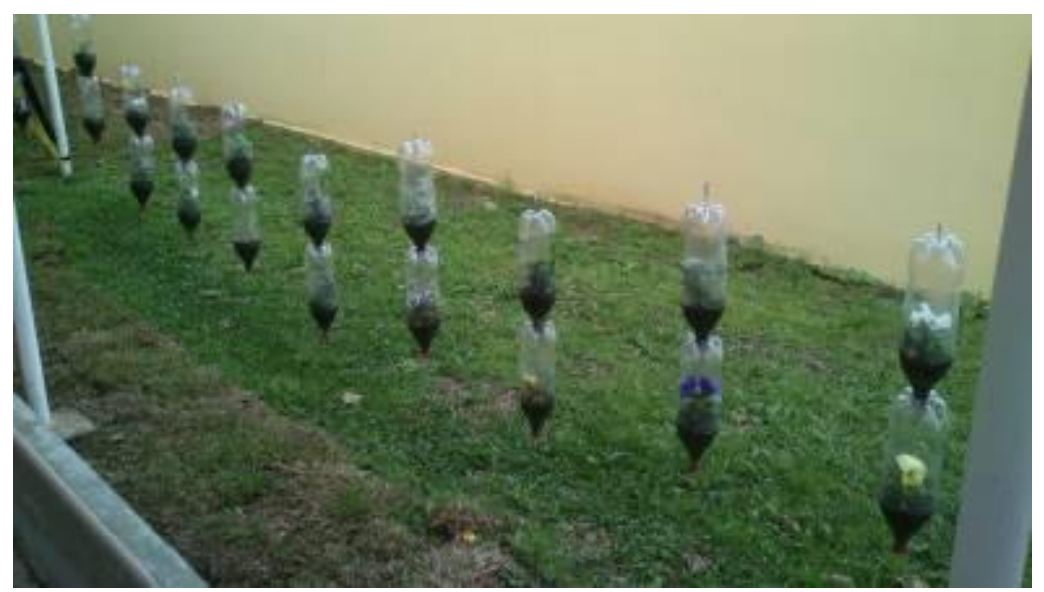

Figura 3: Floreira suspensa confeccionada pelas crianças do pré.

Após a confecção da floreira suspensa e com a chegada de alguns materiais, demos início à pintura da escada do CMEl (Figuras 4 e 5).

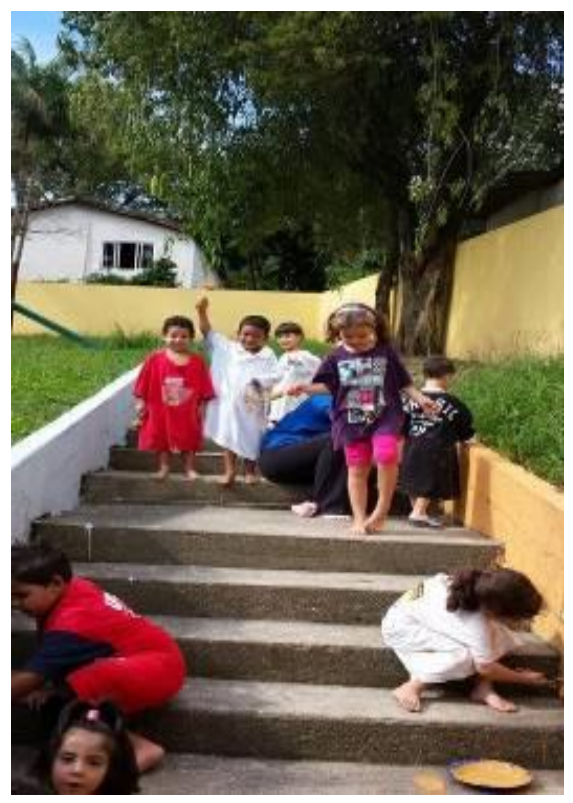

Figura 4: As crianças do pré pintando as escadas e a mureta do CMEI. 


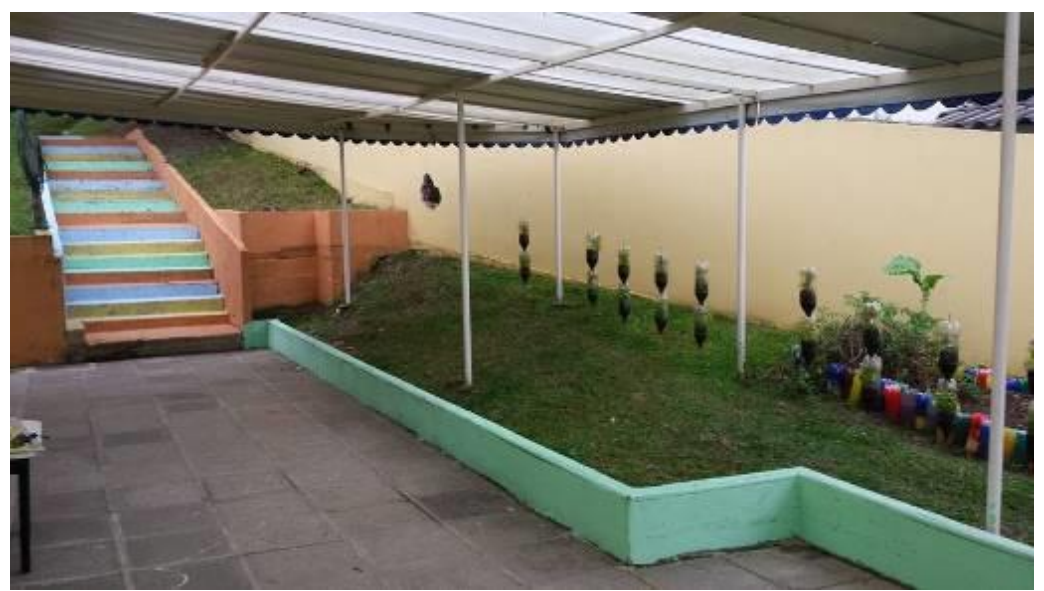

Figura 5: $\mathrm{O}$ trabalho de pintura finalizado, as floreiras e a grama cortada.

Então, demos início a mais uma etapa, pedindo para que as crianças desenhassem como elas queriam o parque de pneus, depois que todos desenharam fizemos uma votação e foi selecionado um desenho para ser o croqui do parque. Após convidamos alguns pais e demos início à colocação dos pneus (Figura 6):

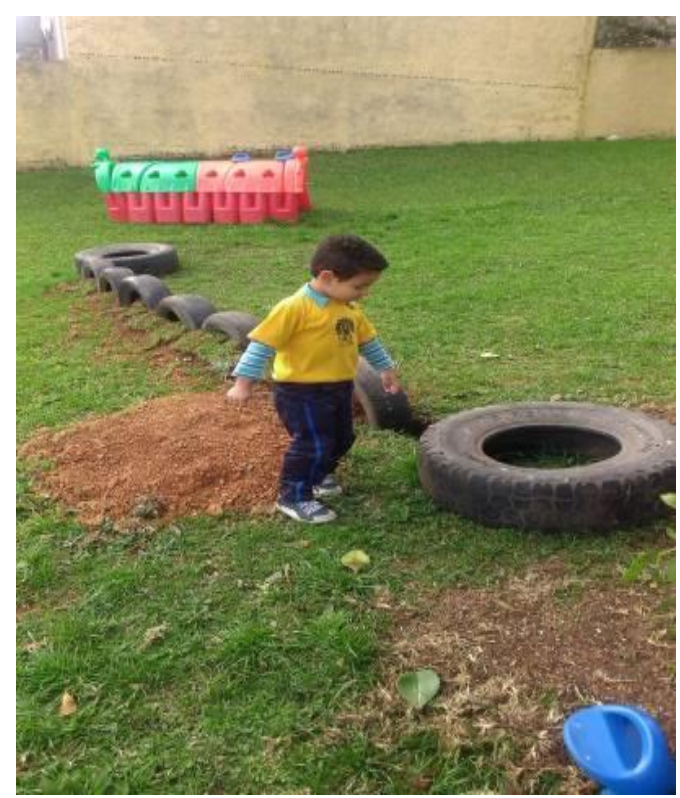

Figura 6: Início da construção do parque de pneus

Percebemos que as crianças adoraram esse momento e brincaram muito nos pneus já colocados, no entanto, o final do ano chegou e não foi possível finalizar o parque e nem as outras ações propostas pelas crianças. Fizemos uma roda de conversa e colocamos essas questões para as crianças, que não daria tempo de terminar e as questionamos se sabiam o porquê? 
Fiquei surpresa ao receber algumas respostas como:

"Os adultos não estão ajudando muito, por isso não dá pra fazer nosso parque" (criança1).

"Se tivesse mais colaboração ia dar tempo"(criança2)

"Vamos fazer uma campanha par ver se alguém ajuda" (criança $3)$.

"Que pena, todas as criancinhas do CMEI iam ficar bem felizes" (criança 4).

Inquestionavelmente, as crianças se envolveram no projeto e sabiam o que queriam fazer, desde o primeiro momento que foram levados ao espaço externo do $\mathrm{CMEI}$, pois esse espaço é deles e para eles.

Ou seja, as crianças se sentem responsáveis pelo espaço do CMEl e devemos sim, contar com a ajuda delas para manter esse espaço, desde a Educação Infantil, para que isso reflita nas atitudes que ela terá com a escola, com o trabalho e com suas relações de maneira geral.

Enfim, deixei o CMEl no início do ano, mas com a certeza de que essa sementinha ficou plantada nas crianças, que também saíram e foram para a escola e, principalmente, nas professoras que estão dando continuidade ao projeto com a nova turma do pré e com a turma do MIII.

\section{Avaliação}

Ao levar em consideração os objetivos que se pretendia atingir no início do trabalho, pode-se dizer que conseguimos ir além, considerando a concepção das professoras e as ações que estas tinham frente ao trabalho com a EA e as propostas que apresentaram ao longo do processo. Pessoalmente, foi gratificante estar envolvida nessa modificação.

Outra questão que chamou muito a minha atenção durante o projeto, foi a quebra de paradigma das professoras que acreditavam que não era possível trabalhar EA com os menores, por acreditar que eles não entendiam e depois estavam fazendo excelentes práticas com essas crianças. Para Cascino (1999) ao instrumentalizar professores para o trabalho:

Os professores saltam da condição de contratado para "treinar", para condição de parceiros que, munido de uma sistematização competente, assumem a cumplicidade de contribuir com a temporalidade - os ritmos - preexistente no ambiente local, reconstruindo os campos relacionais, recriando percepções e perspectivas (p.94). 
Sendo assim, a contribuição dos professores para o desenvolvimento de um trabalho, independente de qual seja é essencial. Contudo, há uma enorme necessidade que esses professores sejam repertoriados para que possam assim, contribuir efetivamente, para a construção do conhecimento.

Um momento de frustração durante o projeto foi quando o grupo decidiu acabar com o projeto de reciclagem, pois eu já trabalhava esse projeto de maneira diferenciada em minha sala, buscando envolver as crianças para que compreendessem a finalidade do mesmo. E a intenção era levar isso para as outras turmas, mas não foi possível.

Além disso, esperava um pouco mais de envolvimento da comunidade para conseguir realizar algumas questões propostas pelas crianças, mas isso não ocorreu. Como poucos pais ajudaram a colocar os pneus, não deu tempo de terminar o parque e as crianças ficaram frustradas, assim como eu, mas por outro lado, aprenderam a lidar com essa situação que nem tudo está ao nosso alcance, que nem sempre as coisas saem como planejamos e isso não deixa de ser um aprendizado.

Neste sentido, pode-ser dizer assim, como Barros e Tozzoni-Reis (2009) que "compreendemos o papel mediador do educador ambiental como um papel que assume a direção - democrática - de um processo que é essencialmente participativo e coletivo. " (p.139) ou seja, é necessário incluir os membros da comunidade e da instituição para que a ação ocorra e esse papel cabe ao educador ambiental.

Também houve um grande avanço no trabalho com a horta, pois no início, as crianças nem iam muito à horta e até o final do ano, elas já estavam decidindo o que plantar, como plantar e o que fazer com o que iam colher. Para Carvalho (2012)

A formação do indivíduo só faz sentido se pensada em relação ao mundo em que ele vive e pelo qual é responsável. Na EA esta tomada de posição de responsabilidade pelo mundo em que vivemos, incluindo aí a responsabilidade com os outros e com o ambiente (2012, p.158).

Portanto, pode-se dizer que, houve um grande crescimento ao me envolver neste projeto, e buscar soluções para determinados problemas, crescimento da equipe, por trabalhar em grupo para decidir ações a serem tomadas para a melhoria do trabalho, por elas mesmas identificarem o que poderiam melhorar. Além de um grande ganho especialmente para as crianças que tiveram a oportunidade de serem protagonistas das ações que desejam, desempenhar no meio que estavam inseridas, ou seja, no CMEI. 


\section{Considerações finais}

Este artigo se insere na temática ambiental a partir da interdisciplinaridade. Para tanto, buscou-se aprofundamento no referencial teórico optando pelo diálogo entre a Educação Infantil e a Educação Ambiental. $O$ referencial teórico também fundamentou a pesquisa-ação que teve como objetivo identificar a percepção que os profissionais possuem sobre o trabalho com a Educação Ambiental e a interdisciplinaridade; sensibilizar os profissionais da instituição a respeito do trabalho com a Educação Ambiental e promover práticas de Educação Ambiental através da interdisciplinaridade.

Empregou-se a pesquisa qualitativa ao Centro Municipal de Educação Infantil, para que se pudesse conhecer o universo pesquisado. Após foi realizada uma entrevista com professoras atuantes nesta instituição, para que fosse possível constatar a concepção das mesmas sobre o trabalho com a EA e como estas realizavam esse trabalho em sua sala de aula.

Em suma, pode-se afirmar que, todas as entrevistadas possuem uma visão naturalista sobre a EA e que o trabalho que desenvolviam era resultado dessa concepção, visto que, eram práticas nas quais as crianças não tinham um papel de protagonista, não se trabalhava a respeito do meio em que estavam inseridas e raramente as crianças eram levadas à reflexão.

Após essa primeira pesquisa, foi realizada uma intervenção com as professoras e pode-se dizer que esta surtiu efeito, pois houve sim, mudança em suas práticas e ao longo do processo até sua concepção sobre como as crianças podem aprender sobre a Educação Ambiental.

Quanto à inserção de práticas de Educação Ambiental através da interdisciplinaridade, estas, com certeza foram efetivadas através de diversas ações realizadas no CMEI como a horta, a revitalização do espaço externo e a construção das floreiras, nas quais as crianças tiveram a oportunidade de experimentar e vivenciar diversas trocas e experiências.

Em síntese, as práticas de EA foram ampliadas nessa instituição e ouve o envolvimento, além das crianças e das professoras, no entanto, é preciso pensar em uma formação para esses profissionais que vá além da sala de aula, pois são eles que estão à frente de inúmeros alunos para fazer a ponte com o conhecimento e é necessário que estes sejam instrumentalizados para que não cheguem às salas de aula com reducionismos e tradicionalismos, mas que ultrapassem essas barreiras para que se efetive a troca de experiências e a construção do conhecimento.

\section{Referências}

BRASIL. Diretrizes Curriculares Nacionais para a Educação Ambiental. Brasília: MEC/CNE, 2012.

BRASIL. Diretrizes Curriculares Nacionais para a Educação Infantil. Brasília, 2010. 
BRASIL. Lei № 9.394, de 20 de dezembro de 1996. Lei de Diretrizes e Bases da educação Brasileira (LDB), Brasília, 1996.

BRASIL. Ministério da Educação e Desporto Secretaria de Educação Fundamental. Referencial Curricular Nacional para a Educação Infantil. v.1, 2 e 3. Brasília: MEC/SEF, 1998.

BRASIL. LEI No 9.795, DE 27 DE ABRIL DE 1999. Política Nacional de Educação Ambiental, Brasília, 1999.

BRASIL. Parâmetros Curriculares Nacionais: meio ambiente. Brasília: MEC/SEF, 1996.

BOFF, L. Sustentabilidade: O que é: o que não é. Rio de Janeiro: Vozes, 2012.

BUJES, M.I.E.. Escola Infantil Pra que te Quero?. In: CRAIDY, C.M.; KAERCHER, G.E.P.S. (orgs). Educação infantil: Pra que te quero? Porto Alegre: Artmed, 2001, cap. 1 p.13-22..

CURITIBA. Diretrizes Curriculares para a Educação Municipal de Curitiba. Volume 2, Curitiba, 2006.1

CARIDE, J.A.; MEIRA, P.A Educação Ambiental e Desenvolvimento Humano. Instituto Piaget, 2001.

CARVALHO, I.C.M. Educação Ambiental a formação do sujeito ecológico. São Paulo: Cortez, 2012.

CRAIDY, C.M.. Educação Infantil e as Novas Definições da Legislação. In CRAIDY, C.M.; KAERCHER, G.E.P.S. (orgs). Educação Infantil: Pra que te quero? Porto Alegre: Artmed, 2001, cap. 2 p.23 - 25.

ELLIOT, J. Recolocando a pesquisa-ação em seu lugar original e próprio. In: GERARDI, C.M.C.; FIORENTINI, D.; PEREIRA, E.M.A. (Org.). Cartografias do trabalho docente: professor (a)-pesquisador(a). Campinas: Mercado de Letras, 1997. p. 137-152.

KRAMER. S. A política do pré-escolar no Brasil: a arte do disfarce. Rio de Janeiro: Achime, 1995.

KULHMANN JR. M. Infância e Educação Infantil: uma abordagem histórica. Porto Alegre: Mediações, 2001.

KULHMANN JR. M. O jardim de infância e a educação das crianças pobres: final do século XIX início do século XX. In: MONARCHA, C. Educação da infância brasileira 1875 - 1983. São Paulo: Autores Associados, 2001.

KULHMANN JR. M. Educação Infantil e Currículo. In: FARIA, A.L.G, PALHARES. M.S. Educação infantil pós LDB: rumos e desafios. São Paulo: Autores Associados

LEFF, E. Saber ambiental: sustentabilidade, racionalidade, complexidade, poder. Petrópolis: Vozes, 2012

revista brasileira educação ambiental 
MEDINA, N.M. Amazônia: uma proposta interdisciplinar de educação ambiental: documentos metodológicos. Brasília: IBAMA, 1994.

MORALES, A.G.M. A formação do profissional educador ambiental: reflexões, possibilidades e constatações. Ponta Grossa: Ed. UEPG, 2009.

MORIN, E. Os sete saberes necessários à educação do futuro. São Paulo: Cortez, 2001.

OLIVEIRA, D.L.H. et al. Horta vertical: Um instrumento de Educação Ambiental na escola. Revista eletrônica do Mestrado em Educação Ambiental. Ed. Especial Jan/Jun.2014

OLIVEIRA, Z.R. Educação Infantil: fundamentos e métodos. São Paulo: Cortez, 2002.

REIGOTA, M. O que é Educação Ambiental. São Paulo: Brasiliense, 2012.

THIOLLENT, M. Metodologia da pesquisa-ação. São Paulo: Cortez, 2000.

TIRIBA, L. Crianças da natureza: Educação Ambiental para Sociedades Sustentáveis, NIMA/PUC-Rio, 2010

TOZONI-REIS, M.F.C. et al. Educação Ambiental a várias mãos: educação escolar, currículo e políticas públicas. Araraquara, SP: Junqueira\&Marin, 2014.

TOZONI-REIS, M.F.C. Educação Ambiental: natureza, razão e história. São Paulo: Autores associados, 2008. 